\title{
Review Article \\ The Central Effects of Thyroid Hormones on Appetite
}

\author{
Anjali Amin, Waljit S. Dhillo, and Kevin G. Murphy \\ Section of Investigative Medicine, Faculty of Medicine, Imperial College London, 6th Floor, Commonwealth Building, \\ Hammersmith Hospital, Du Cane Road, London W12 0NN, UK
}

Correspondence should be addressed to Kevin G. Murphy, k.g.murphy@imperial.ac.uk

Received 21 December 2010; Accepted 31 March 2011

Academic Editor: Carmen C. Solorzano

Copyright () 2011 Anjali Amin et al. This is an open access article distributed under the Creative Commons Attribution License, which permits unrestricted use, distribution, and reproduction in any medium, provided the original work is properly cited.

\begin{abstract}
Obesity is a major public health issue worldwide. Current pharmacological treatments are largely unsuccessful. Determining the complex pathways that regulate food intake may aid the development of new treatments. The hypothalamic-pituitary-thyroid (HPT) axis has well-known effects on energy expenditure, but its role in the regulation of food intake is less well characterised. Evidence suggests that the HPT axis can directly influence food intake. Thyroid dysfunction can have clinically significant consequences on appetite and body weight. Classically, these effects were thought to be mediated by the peripheral effects of thyroid hormone. However, more recently, local regulation of thyroid hormone in the central nervous system (CNS) is thought to play an important role in physiologically regulating appetite. This paper focuses on the role of the HPT and thyroid hormone in appetite and provides evidence for potential new targets for anti-obesity agents.
\end{abstract}

\section{Introduction}

Obesity, its complications, and the associated mortality are major public health issues worldwide. The major central nervous system (CNS) areas important in the regulation of appetite are the hypothalamus and brainstem. The hypothalamus interprets and integrates afferent signals from the periphery and brainstem to modulate efferent signals that regulate food intake and energy expenditure. Neural and hormonalperipheral signals communicate information including acute nutritional states and energy stores. The hypothalamus is subdivided into a number of interconnecting nuclei, including the paraventricular nucleus (PVN), the ventromedial nucleus (VMN), and the arcuate nucleus (ARC), which are particularly important in regulating energy homeostasis. The ARC is located near the median eminence, where the blood-brain barrier is incomplete, and is thus well positioned to respond to circulating factors involved in appetite and food intake [1]. Recent evidence suggests that thyroid hormones may access the ARC and other regions of the hypothalamus to regulate appetite (Figure 1).

It is well established that the hypothalamic-pituitarythyroid (HPT) axis regulates body weight. Thyroid hormones are known to effect metabolic rate. Thyroid dysfunction can have clinically significant consequences on appetite and body weight. Hypothyroidism classically causes reduced basal energy expenditure [2] with weight gain $[3,4]$. Conversely, hyperthyroidism increases energy expenditure and reduces body weight [5-7]. Traditionally, it has been assumed that it is this reduced body weight that drives the hyperphagia that can be a presenting feature in hyperthyroidism. However, recent evidence suggests that the HPT axis may play a direct role in the hypothalamic regulation of appetite, independent of effects on energy expenditure. Classically, hypothalamic thyrotropin-releasing hormone (TRH) stimulates thyroid-stimulating hormone (TSH) release from the anterior pituitary gland, which then stimulates the release of both thyroid hormones, triiodothyronine (T3) and thyroxine (T4). Reports suggest that all of these signalling molecules can directly influence food intake [8-11]. Improved understanding of the role of the HPT axis and thyroid hormone in appetite may identify new targets for antiobesity agents.

\section{Effects of Thyroid Hormones on Food Intake (Table 1)}

There are well-characterised effects of fasting on hypothalamic TRH expression. This is primarily thought to downregulate the HPT axis in periods of limited food availability, 


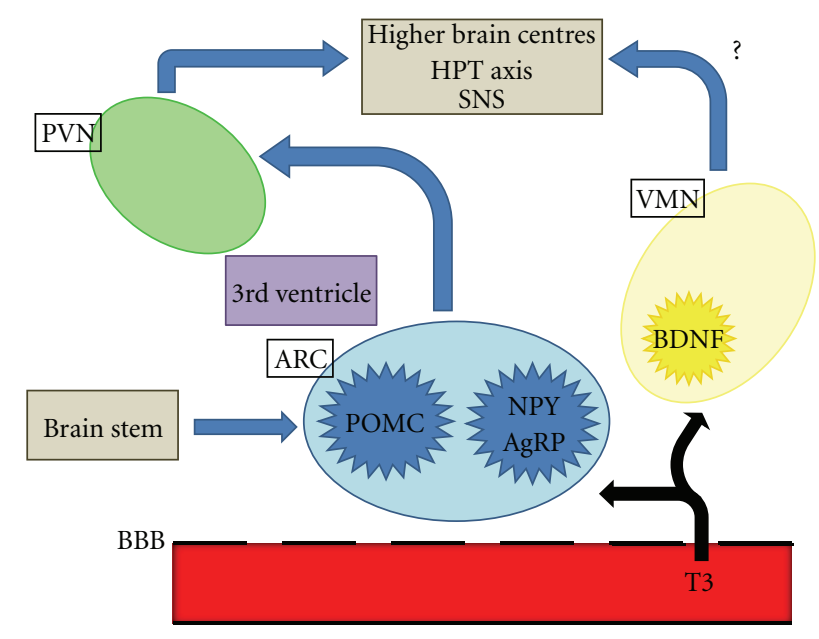

Figure 1: Schematic diagram of central appetite regulation. T3 can access the hypothalamus and brainstem via the incomplete blood brain barrier. PVN: paraventricular nucleus; ARC: arcuate nucleus; VMN: ventromedial nucleus; BBB: blood-brain barrier; T3: triiodothyronine; POMC: Pro-opiomelanocortin; NPY: neuropeptide Y; AgRP: agouti-related protein; BDNF: brain-derived neurotrophic factor; HPT: hypothalamic-pituitary thyroid; SNS: sympathetic nervous system.

thus reducing food intake. However, TRH has been reported to have direct anorectic effects, suggesting it may regulate food intake independent of effects on the HPT axis. In rodents, central administration of TRH reduces food intake $[8,12,13]$; similar effects on food intake are seen following peripheral administration [14].

TSH has also been shown to reduce food intake when injected centrally into rats [8]. There is evidence that TSH from the pars tuberalis is involved in the photoperiodic response in birds and rodents, and it is thus possible that TSH is involved with the seasonal alterations in food intake and body weight that occur in some species [15-17].

The hyperphagia associated with hyperthyroidism may be a result of thyroid hormones acting directly on CNS appetite circuits. T3 directly stimulates food intake at the level of the hypothalamus. In rodent models, peripheral and central hypothalamic administration of $\mathrm{T} 3$ increases food intake [9-11].

There are several mechanisms postulated to mediate the orexigenic effects of thyroid hormones. The ARC contains two distinct energy homeostasis-regulating neuronal populations. One subpopulation expresses the proopiomelanocortin (POMC) gene which codes for the anorectic neuropeptide alpha-melanocyte-stimulating hormone $(\alpha-\mathrm{MSH})$. The other expresses the orexigenic factors neuropeptide Y (NPY) and agouti-related protein (AgRP). It has been reported that peripheral administration of T3 increases hypothalamic NPY mRNA and that intracerebroventricular (ICV) administration of a NPY Y1 receptor antagonist blunts T3 induced hyperphagia, suggesting that T3 may increase appetite via NPY [10]. T3 administration was also reported toalso reduce hypothalamic POMC expression [10]. Another study did not detect changes in hypothalamic neuropeptide
TABle 1: Effect of TRH, TSH, and T3 on food intake. Central administration of TRH and TSH in rodents causes a reduction in food intake $[8,12,13]$; similar effects on food intake are seen following peripheral administration of TRH [14]. Central and peripheral administration of T3 increases food intake [9-11]. TRH: thyrotropin releasing hormone; TSH: thyroid-stimulating hormone; T3: triiodothyronine.

\begin{tabular}{lc}
\hline Hormone & Effect on food intake \\
\hline TRH & $\downarrow$ \\
TSH & $\downarrow$ \\
T3 & $\uparrow$ \\
\hline
\end{tabular}

expression in response to peripheral administration of T3 though this may reflect the different doses of $\mathrm{T} 3$ administered [9].

However, the effects of thyroid hormones on food intake may not be mediated directly by the ARC. Direct administration of T3 into the VMN but not the ARC increases food intake in rats [9]. As appetite regulating circuits in the ARC are known to be altered by changes in the HPT, there may be an indirect effect of the ARC via the VMN allowing intra-VMN T3 to increase food intake. In keeping with this, there are excitatory inputs into POMC neurons that originate in the VMN [18].

The effects of T3 in the VMN may be mediated by glutamate [19] and/or brain-derived neurotrophic factor (BDNF) neurons [20]. The VMN is likely to be the source of glutamatergic neurons that modulate ARC POMC neurons. It has not been investigated whether T3, for example, inhibits glutamate synthesis and/or release to disrupt excitatory input into POMC neurons. However, it is interesting to note that there is evidence from other tissues that HPT activity can regulate glutamatergic neuronal machinery. For example, hypothyroidism increases expression of the vesicular glutamate transporter vGLUT-2 in the anterior pituitary [21]. BDNF is a protein belonging to the neurotrophin family of growth factors, which regulate growth, differentiation and survival of neurons. BDNF is highly expressed in the VMN and is reduced by $60 \%$ with fasting chronic ICV administration of BDNF significantly reduces food intake in rats [22]. BDNF is thought to act via the tyrosine kinase receptor TrkB. In accord with this, rodents with reduced TrkB expression develop hyperphagia and obesity [23]. In vitro data suggest that $\mathrm{T} 3$ reduces BDNF gene expression when applied to hypothalamic explants [20]. However, VMN BDNF may not be physiologically important in the regulation of food intake. Steroidogenic factor-1 (SF1) is a transcription factor which is expressed in of the VMN and which is often used as a molecular marker for the VMN. Leptin depolarizes and increases the firing rate of VMN SF1 neurons, suggesting they are involved in the regulation of energy homeostasis. Mice specifically lacking BDNF in SF1 neurons do not develop the obese phenotype observed in other BDNF-deficient models, suggesting that VMN BDNF may not play an important role in food intake [24]. Further work is required to determine the role of BDNF in mediating the effects of $\mathrm{T} 3$ on appetite. 


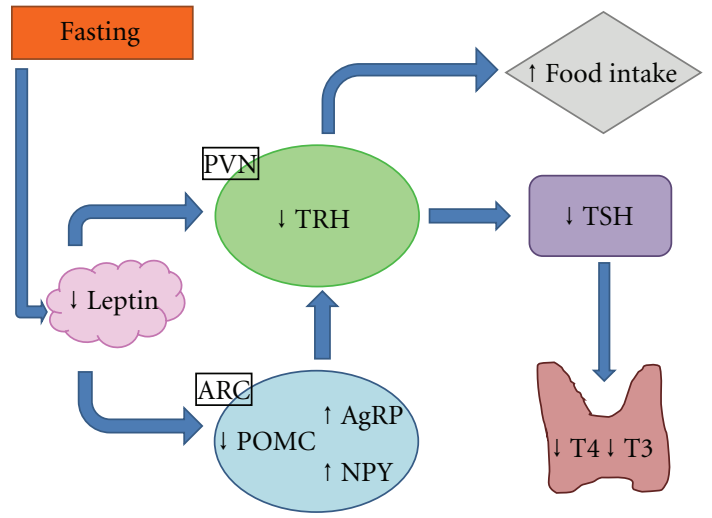

Figure 2: Effect of fasting on the hypothalamo-pituitary-thyroid axis. PVN: paraventricular nucleus; ARC: arcuate nucleus; TRH: thyrotropin releasing hormone; TSH: Thyroid-stimulating hormone; T3: triiodothyronine; T4: thyroxine; POMC: Pro-opiomelanocortin; NPY: neuropeptide Y; AgRP: agouti-related protein.

The enzyme $5^{\prime}$ adenosine monophosphate-activated protein kinase (AMPK) is thought to act as a sensor which regulates cellular energy homeostasis. AMPK is activated by phosphorylation, and AMPK activation in the ARC increases food intake [25]. Peripherally administered T3 increases hypothalamic AMPK phosphorylation, which thus may mediate the orexigenic effects of T3 [11].

Thyroid hormone derivatives have also been implicated in the regulation of appetite. G protein-coupled trace amine-associated receptor 1 (TAAR1) is expressed in the rat hypothalamus and is associated with the regulation of energy homeostasis. Thyroid hormone derivative 3-iodothyronamine (T1AM), an endogenous biogenic amine, is a potent agonist of TAAR1. Rodent studies show that T1AM significantly increases food intake in rats, when administered intraperitoneally, ICV, or directly into the ARC [26]. However, the physiological relevance of these effects remains unknown.

The thyroid hormone receptor (TR) or receptors that mediate the effects of thyroid hormones on appetite are unknown. There are two main types of thyroid hormone receptors - thyroid hormone receptor $\alpha$ (THRA) and thyroid hormone receptor $\beta$ (THRB), each coded by a distinct gene. These genes are alternately spliced to generate three major highly homologous nuclear receptor isoforms (TR $\alpha 1$, TR $\beta 1$, and TR $\beta 2$ ) with specific tissue distributions [27]. The three main isoforms bind T3 with high affinity, and regulate thyroid hormone-mediated transcription. TR $\alpha$ is the main isoform regulating T3 activity in the heart, skeletal muscle, bone and brain; TR $\beta$ is the main isoform regulating T3 activity in the liver. Adipose tissue expresses both TR $\alpha$ and $\operatorname{TR} \beta$. TR $\beta 1$ is expressed in most tissues, whilst TR $\beta 2$ is expressed solely in the hypothalamus, pituitary, cochlea, and retina $[28,29]$. All three isoforms are expressed in the human hypothalamus in a number of nuclei, including the infundibular nucleus, the human equivalent of the ARC, and the supraoptic and paraventricular nuclei.
Although thyroid hormones can directly increase food intake in the hypothalamus, selectively targeting TR subtypes have been shown to have beneficial metabolic effects. Activation of the TR $\beta$ receptor reduces body weight in obese rats [30], which may be a result of an increase in metabolic rate. Hence, TR $\beta$ agonists have been proposed as treatments for obesity. Targeting the TR with a TR $\beta$-selective agonist may determine whether these agents address the metabolic effects of thyroid hormone, without effects on the TR $\alpha$-expressing tissues such as the heart [30]. Peripheral administration of a TR $\beta$-selective agonist to rats during feeding with a highfat diet prevents the expected increases in fat mass, glucose intolerance, and hypertriglyceridaemia [31]. These effects may reflect the increased energy expenditure observed in rodents treated with a TR $\beta$-selective agonist rather than the effects of thyroid hormones on appetite [32]. Further work is required to identify the receptor responsible for the orexigenic effects of $\mathrm{T} 3$ in the hypothalamus.

\section{Effects of Nutritional State on Thyroid Hormones}

Reduction in TRH in response to fasting may be important as TRH is seen to have a direct anorectic effect when injected into the hypothalamus [13]. It is possible there are distinct TRH neuronal populations regulating the HPT axis and regulating appetite.

In periods of limited food availability, there is central downregulation of the HPT axis. Serum T4 and T3 levels fall during fasting in humans [33] and rodents [34, 35]. As the majority of $\mathrm{T} 3$ in rodents comes from the thyroid gland, it is thought food deprivation may result in a fall in the release of T4 and T3. This is likely secondary to a reduction in hypothalamic TRH expression, an effect that may be mediated by the adipose hormone leptin (Figure 2).

Leptin is an adipocytokine that circulates in proportion to white adipose tissue and communicates information regarding body fat stores to the CNS. Administration of leptin can reverse starvation induced changes of the HPT axis $[34,36,37]$. Leptin administration partially prevents the reduction in total T4 clearly observed in fasted mice [34]. Humans and mice with mutations of leptin receptor or leptin itself exhibit central hypothyroidism [38, 39], which is ameliorated in leptin-deficient humans by the administration of leptin [40]. Leptin may directly regulate TRH expression in the PVN and may indirectly regulate TRH via effects in the ARC. Leptin increases $\alpha$-MSH release and decreasesAgRP release, which results in a downregulation of TRH expression. There is also emerging evidence of the existence of a melanocortin-independent pathway by which leptin can influence the HPT axis; cotreatment with a potent melanocortin 4 receptor (MC4R) antagonist diminishes but does not fully block leptin action in restoring total T4 in a rodent model [41].

However, the changes in the HPT axis and peripheral thyroid hormone levels are at odds with the reported effects of thyroid hormones on appetite. If thyroid hormones physiologically increase appetite, they would be predicted to increase, rather than decrease in starvation. Evidence 


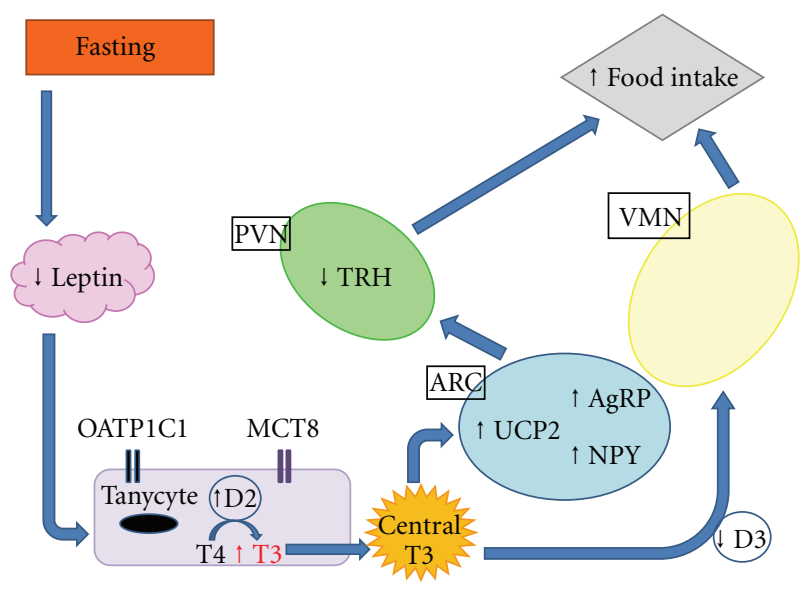

Figure 3: Effect and consequences of fasting on central T3 levels, mediated by D2 and D3. PVN: paraventricular nucleus; ARC: arcuate nucleus; VMN: ventromedial nucleus; TRH: thyrotropin releasing hormone; T4: thyroxine; T3: triiodothyronine; OATP1C1: Organic anion transporting polypeptide 1c1; MCT8: monocarboxylate transporter 8; D2: Deiodinase 2; D3: deiodinase 3; NPY: Neuropeptide Y; AgRP: agouti-related protein; UCP2: uncoupling protein 2 .

suggests that rather than systemic thyroid hormone levels, it is local CNS concentrations of thyroid hormones that are important in the regulation of appetite.

\section{Central Changes in T3 Levels Mediated by D2 and D3}

A group of enzymes known as the deiodinases (thioredoxin fold enzymes) regulates the activation and inactivation of T3 and T4. These enzymes are responsible for regulating centralthyroid hormone levels. There are three types of deiodinase, each with an active site containing the amino acid selenocysteine, which is critical for the deiodination reaction catalysed by these enzymes. Deiodinases act by selectively removing of iodine from $\mathrm{T} 4$ and its derivatives. Iodine may be removed from the inner (tyrosyl) or outer (phenolic) ring. Deiodinase 1 (D1) is expressed predominantly in the liver, kidney, and thyroid in humans and rodents. However, Deiodinase 2 (D2) and Deiodinase 3 (D3) are highly expressed within the CNS, with some peripheral expression. The expression of each enzyme is regulated individually by thyroid hormone. Within the hypothalamus, expression and activity of D2 and D3 depend on nutritional circumstances, leading to tissue specific changes in hypothalamic T3 availability that may be important in the regulation of food intake and energy expenditure (Figure 3 ).

D2 catalyses the conversion of $\mathrm{T} 4$ to $\mathrm{T} 33$ to generate intracellular T3 [42]. It is particularly important in the brain. D2 plays an important part in thyroid hormonemediated feedback regulation of TRH production. Dio2 knockout mice have higher levels of serum T4 and TSH; however, administration of T3, but not T4, suppresses TSH, suggesting central T4 resistance [43]. Hence the activity of
D2 is crucial in the feedback regulation of TSH secretion. T3-driven suppression of TRH expression in the PVN [44] can be prevented by infusion of the D2 inhibitor iopanoic acid [45]. D2 is not expressed in hypophysiotropic neurons [46] but is highly expressed in tanycytes [47], specialised endothelial cells which line the third ventricle. Tanycytes express two thyroid hormone specific transporters: monocarboxylate transporter 8 (MCT8) and organic anion transporting polypeptide $1 \mathrm{C} 1$ (OATP1C1) in rodent models [48]. D2 mediates the conversion of $\mathrm{T} 4$ to $\mathrm{T} 3$ within these tanycytes, allowing $\mathrm{T} 3$ to access the TRH neurons of the PVN. MCT8 is thought to modulate neuronal uptake of thyroid hormone in mice [49], ensuring that TRH production is regulated by peripheral T4 concentration, under basal conditions. Expression of Dio2 and D2 activity are increased in hypothyroidism [50] and fall with the administration of $\mathrm{T} 4$, protecting tissues from the adverse effects of extremes of thyroid dysfunction [51].

Hypothalamic D2 expression is not just regulated by thyroid status. In rodents, fasting also increases hypothalamic D2 expression and activity $[9,37]$, and this effect is not reversed by systemic administration of $\mathrm{T} 4$ [45]. It can, however, be reversed by leptin administration [37], suggesting it is more important in energy homeostasis than the HPT axis. Leptin restores the hypothalamic and pituitary components of the HPT axis during fasting, but directly blunts the response of the thyroidgland, resulting in low plasma T4 and T3 [37]. Hence, normalization of thyroid hormone may depend on changes in deiodinase activities and the long-term thyroid stimulation by TSH to oppose these direct inhibitory effects of leptin on the thyroid.

D2 activity is particularly high in the ARC and median eminence [52], where it is expressed within astrocytes and tanycytes. The processes of the D2 containing tanycytes are in direct contact with NPY/AgRP neurons of the ARC which also express UCP2 [53]. Uncoupling protein 1 (UCP1) is thought to be integral to the process of brown-fat-associated nonshivering thermogenesis, as it dissipates energy in the form of heat [54]. The role of inner mitochondrial membrane uncoupling protein 2 (UCP2) is less well defined and tissue specific, but it is subject to regulation by T3 [55].

T3 is thought to access CNS target neurons via a number of different mechanisms. One is through a direct crossing of the blood-brain barrier (BBB). Alternatively T3 may cross the $\mathrm{BBB}$ via astrocytes encircling endothelial cells, following $5^{\prime}$ deiodination of T4 taken up from the blood. Astrocytes in the ARC are of particular importance as they express leptin receptors [56, 57]. Another postulated mechanism of T3 transport to target neurons is hypothalamic thyroid hormone uptake from the CSF, with thyroid hormone being taken up from the CSF in the third ventricle and transported by tanycytes to neurons in the ARC that project to TRH cells in the PVN [58]. Upregulation of ARC D2 activity during food deprivation causes increased local bioavailability of $\mathrm{T} 3$ in the ARC, leading to increased UCP2 activity and mitochondrial proliferation within the NPY/AgRP neurons [53]. In Dio2 null mice, food deprivation does not result in the characteristic increase in hypothalamic NPY expression [53], suggesting that D2-driven T3 production is crucial to 
maintain the normal hypothalamic response to fasting. TSH from the pars tuberalis induces Dio2 expression in the mouse hypothalamus as part of the photoperiodic response, and this may thus increase hypothalamic T3 levels [16]. However, it is currently unknown whether these changes are responsible for photoperiodic changes in food intake.

$\mathrm{D} 3$ is responsible for the inactivation of $\mathrm{T} 4$ to $\mathrm{rT} 3$ and T3 to $3^{\prime}, 3^{\prime}$-diiodothyronine (T2) by inner-ring deiodination [59]. D3 preferentially uses T3 as a substrate rather than T4. D3 is predominantly expressed in the adult CNS [60] but is also expressed in the placenta, pregnant uterus, and fetal tissues. D3 mRNA is expressed in the rat hypothalamus and other CNS regions [61]. In the CNS, D3 activity is mediated by levels of thyroid hormone, with higher levels in hyperthyroidism and lower levels in hypothyroidism [61]. Expression of D3 in peripheral tissues is relatively low, but it can be induced in the liver and skeletal muscle of critically ill patients and has been postulated to be responsible for the characteristic changes of reduced levels of TSH and thyroid hormone seen in the sick euthyroid syndrome [62]. D3 may also play a role in the regulation of food intake. Hibernating Siberian hamsters show significant changes in food intake and energy expenditure depending on photoperiod. During short photoperiod days, which would naturally occur during winter months they have reduced food intake and body weight and their core body temperature falls [63]. Expression and activity of hypothalamic D3 is increased in these animals during the same period, causing a reduction in local bioavailability of T3. The reductions in food intake and body weight can be reversed by the implantation of a T3 pellet into the dorsomedial hypothalamus, suggesting that it may be the changes in hypothalamic D3 that is responsible for these effects on energy homeostasis [64].

\section{Summary}

Local regulation of thyroid hormones in the CNS may physiologically regulate appetite. Switching between the induction of D2 and D3 expression may finely control hypothalamic thyroid hormone concentrations. Further work is now required in order to characterise the pathways by which thyroid hormones regulate food intake. Determining the mechanisms by which thyroid hormones regulate energy homeostasis may aid the development of therapies for the management of obesity.

\section{Abbreviations}

T2: $\quad 3^{\prime}, 3^{\prime}$-diiodothyronine

AMPK: $5^{\prime}$ adenosine monophosphate-activated protein kinase

AgRP: Agouti-related protein

$\alpha$-MSH: Alpha-melanocyte-stimulating hormone

ARC: Arcuate nucleus

BBB: Blood-brain barrier

BDNF: Brain-derived neurotrophic factor

CNS: Central nervous system

D1: Deiodinase 1
Dio1: Deiodinase 1 gene

D2: $\quad$ Deiodinase 2

Dio2: Deiodinase 2 gene

D3: $\quad$ Deiodinase 3

Dio3: $\quad$ Deiodinase 3 gene

HPT: Hypothalamic-pituitary-thyroid

ICV: Intracerebroventricular

IP: Intraperitoneal

MC4R: Melanocortin 4 receptor

MCT8: $\quad$ Monocarboxylate transporter 8

NPY: $\quad$ Neuropeptide $Y$

OATP1C1: Organic anion transporting polypeptide 1c1

PVN: Paraventricular nucleus

POMC: Pro-opiomelanocortin

rT3: $\quad$ Reverse T3

SF1: $\quad$ Steroidogenic factor-1

TR: $\quad$ Thyroid hormone receptor

TSH: Thyroid-stimulating hormone

TRH: $\quad$ Thyrotropin Releasing Hormone

T4: $\quad$ Thyroxine

T3: $\quad$ Tri-iodothyronine

UCP1: Uncoupling protein 1

UCP2: Uncoupling protein 2

VMN: Ventromedial nucleus.

\section{Acknowledgments}

A. Amin is supported by the National Institute for Health Research (NIHR) Biomedical Research Centre Funding Scheme. W. S. Dhillo is funded by a National Institute for Health Research Clinician Scientist Award and a Wellcome Trust Value in People Award. K. G. Murphy receives funding from the Biotechnology and Biological Sciences Research Council (BBSRC). The Department is funded by the National NIHR Biomedical Research Centre Funding Scheme, the BBSRC and under FP7-HEALTH-2009-241592 (European Union) EurOCHIP.

\section{References}

[1] M. Fry and A. V. Ferguson, "The sensory circumventricular organs: brain targets for circulating signals controlling ingestive behavior," Physiology and Behavior, vol. 91, no. 4, pp. 413423, 2007.

[2] M. Wolf, A. Weigert, and G. Kreymann, "Body composition and energy expenditure in thyroidectomized patients during short-term hypothyroidism and thyrotropin-suppressive thyroxine therapy," European Journal of Endocrinology, vol. 134, no. 2, pp. 168-173, 1996.

[3] N. Manji, K. Boelaert, M. C. Sheppard, R. L. Holder, S. C. Gough, and J. A. Franklyn, "Lack of association between serum TSH or free T4 and body mass index in euthyroid subjects," Clinical Endocrinology, vol. 64, no. 2, pp. 125-128, 2006.

[4] S. Iossa, L. Lionetti, M. P. Mollica, A. Barletta, and G. Liverini, "Thermic effect of food in hypothyroid rats," Journal of Endocrinology, vol. 148, no. 1, pp. 167-174, 1996. 
[5] S. Alton and B. P. O’Malley, "Dietary intake in thyrotoxicosis before and after adequate carbimazole therapy; The impact of dietary advice," Clinical Endocrinology, vol. 23, no. 5, pp. 517520, 1985.

[6] H. Pijl, P. H. E. M. De Meijer, J. Langius et al., "Food choice in hyperthyroidism: potential influence of the autonomic nervous system and brain serotonin precursor availability," Journal of Clinical Endocrinology and Metabolism, vol. 86, no. 12, pp. 5848-5853, 2001.

[7] L. P. Klieverik, C. P. Coomans, E. Endert et al., “Thyroid hormone effects on whole-body energy homeostasis and tissue-specific fatty acid uptake in vivo," Endocrinology, vol. 150, no. 12, pp. 5639-5648, 2009.

[8] M. T. Lin, P. C. Chu, and S. Y. Leu, "Effects of TSH, TRH, LH and LHRH on thermoregulation and food and water intake in the rat," Neuroendocrinology, vol. 37, no. 3, pp. 206-211, 1983.

[9] W. M. Kong, N. M. Martin, K. L. Smith et al., "Triiodothyronine stimulates food intake via the hypothalamic ventromedial nucleus independent of changes in energy expenditure," Endocrinology, vol. 145, no. 11, pp. 5252-5258, 2004.

[10] S. Ishii, J. Kamegai, H. Tamura, T. Shimizu, H. Sugihara, and S. Oikawa, "Hypothalamic neuropeptide Y/Y1 receptor pathway activated by a reduction in circulating leptin, but not by an increase in circulating ghrelin, contributes to hyperphagia associated with triiodothyronine-induced thyrotoxicosis," Neuroendocrinology, vol. 78, no. 6, pp. 321-330, 2003.

[11] S. Ishii, J. Kamegai, H. Tamura, T. Shimizu, H. Sugihara, and S. Oikawa, "Triiodothyronine (T3) stimulates food intake via enhanced hypothalamic AMP-activated kinase activity," Regulatory Peptides, vol. 151, no. 1-3, pp. 164-169, 2008.

[12] E. Vijayan and S. M. McCann, "Suppression of feeding and drinking activity in rats following intraventricular injection of thyrotropin releasing hormone (TRH)," Endocrinology, vol. 100, no. 6, pp. 1727-1729, 1977.

[13] T. Suzuki, H. Kohno, T. Sakurada, T. Tadano, and K. Kisara, "Intracranial injection of thyrotropin releasing hormone (TRH) suppresses starvation-induced feeding and drinking in rats," Pharmacology Biochemistry and Behavior, vol. 17, no. 2, pp. 249-253, 1982.

[14] Y. H. Choi, D. Hartzell, M. J. Azain, and C. A. Baile, “TRH decreases food intake and increases water intake and body temperature in rats," Physiology and Behavior, vol. 77, no. 1, pp. 1-4, 2002.

[15] L. C. Drickamer, "Seasonal variation in litter size, bodyweight and sexual maturation in juvenile female house mice (Mus musculus)," Laboratory Animals, vol. 11, no. 3, pp. 159-162, 1977.

[16] H. Ono, Y. Hoshino, S. Yasuo et al., "Involvement of thyrotropin in photoperiodic signal transduction in mice," Proceedings of the National Academy of Sciences of the United States of America, vol. 105, no. 47, pp. 18238-18242, 2008.

[17] N. Nakao, H. Ono, T. Yamamura et al., "Thyrotrophin in the pars tuberalis triggers photoperiodic response," Nature, vol. 452, no. 7185, pp. 317-322, 2008.

[18] S. M. Sternson, G. M. G. Shepherd, and J. M. Friedman, "Topographic mapping of VMH $\rightarrow$ arcuate nucleus microcircuits and their reorganization by fasting," Nature Neuroscience, vol. 8, no. 10, pp. 1356-1363, 2005.

[19] D. R. Ziegler, W. E. Cullinan, and J. P. Herman, "Distribution of vesicular glutamate transporter mRNA in rat hypothalamus," Journal of Comparative Neurology, vol. 448, no. 3, pp. 217-229, 2002.
[20] M. S. Byerly, J. Simon, E. Lebihan-Duval, M. J. Duclos, L. A. Cogburn, and T. E. Porter, "Effects of BDNF, T, and corticosterone on expression of the hypothalamic obesity gene network in vivo and in vitro," American Journal of Physiology, vol. 296, no. 4, pp. R1180-R1189, 2009.

[21] E. Hrabovszky, I. Kalló, G. F. Turi et al., "Expression of vesicular glutamate transporter-2 in gonadotrope and thyrotrope cells of the rat pituitary. Regulation by estrogen and thyroid hormone status," Endocrinology, vol. 147, no. 8, pp. 38183825, 2006.

[22] P. A. Lapchak and F. Hefti, "BDNF and NGF treatment in lesioned rats: effects on cholinergic function and weight gain," NeuroReport, vol. 3, no. 5, pp. 405-408, 1992.

[23] S. G. Kernie, D. J. Liebl, and L. F. Parada, "BDNF regulates eating behavior and locomotor activity in mice," EMBO Journal, vol. 19, no. 6, pp. 1290-1300, 2000.

[24] H. Dhillon, J. M. Zigman, C. Ye et al., "Leptin directly activates $\mathrm{SF} 1$ neurons in the $\mathrm{VMH}$, and this action by leptin is required for normal body-weight homeostasis," Neuron, vol. 49, no. 2, pp. 191-203, 2006.

[25] Y. Minokoshi, T. Shiuchi, S. Lee, A. Suzuki, and S. Okamoto, "Role of hypothalamic AMP-kinase in food intake regulation," Nutrition, vol. 24, no. 9, pp. 786-790, 2008.

[26] W. S. Dhillo, G. A. Bewick, N. E. White et al., "The thyroid hormone derivative 3-iodothyronamine increases food intake in rodents," Diabetes, Obesity and Metabolism, vol. 11, no. 3, pp. 251-260, 2009.

[27] M. A. Lazar, "Thyroid hormone receptors: multiple forms, multiple possibilities," Endocrine Reviews, vol. 14, no. 2, pp. 184-193, 1993.

[28] M. Sjoberg, B. Vennstrom, and D. Forrest, "Thyroid hormone receptors in chick retinal development: differential expression of mRNAs for $\alpha$ and $\mathrm{N}$-terminal variant $\beta$ receptors," Development, vol. 114, no. 1, pp. 39-47, 1992.

[29] R. A. Hodin, M. A. Lazar, and W. W. Chin, "Differential and tissue-specific regulation of the multiple rat c-erbA messenger RNA species by thyroid hormone," Journal of Clinical Investigation, vol. 85, no. 1, pp. 101-105, 1990.

[30] G. Bryzgalova, S. Effendic, A. Khan et al., "Anti-obesity, antidiabetic, and lipid lowering effects of the thyroid receptor $\beta$ subtype selective agonist KB-141," Journal of Steroid Biochemistry and Molecular Biology, vol. 111, no. 3-5, pp. 262-267, 2008.

[31] B. S. Amorim, C. B. Ueta, B. C. G. Freitas et al., "A TR $\beta$ selective agonist confers resistance to diet-induced obesity," Journal of Endocrinology, vol. 203, no. 2, pp. 291-299, 2009.

[32] C. M. Villicev, F. R. S. Freitas, M. S. Aoki et al., "Thyroid hormone receptor $\beta$-specific agonist GC-1 increases energy expenditure and prevents fat-mass accumulation in rats," Journal of Endocrinology, vol. 193, no. 1, pp. 21-29, 2007.

[33] J. L. Chan, K. Heist, A. M. DePaoli, J. D. Veldhuis, and C. S. Mantzoros, "The role of falling leptin levels in the neuroendocrine and metabolic adaptation to short-term starvation in healthy men," Journal of Clinical Investigation, vol. 111, no. 9, pp. 1409-1421, 2003.

[34] R. S. Ahlma, D. Prabakaran, C. Mantzoros et al., "Role of leptin in the neuroendocrine response to fasting," Nature, vol. 382, no. 6588, pp. 250-252, 1996.

[35] G. Légràdi, C. H. Emerson, R. S. Ahima, J. S. Flier, and R. M. Lechan, "Leptin prevents fasting-induced suppression of prothyrotropin-releasing hormone messenger ribonucleic acid in neurons of the hypothalamic paraventricular nucleus," Endocrinology, vol. 138, no. 6, pp. 2569-2576, 1997. 
[36] M. Rosenbaum, E. M. Murphy, S. B. Heymsfield, D. E. Matthews, and R. L. Leibel, "Low dose leptin administration reverses effects of sustained weight-reduction on energy expenditure and circulating concentrations of thyroid hormones," Journal of Clinical Endocrinology and Metabolism, vol. 87, no. 5, pp. 2391-2394, 2002.

[37] R. L. Araujo, B. M. Andrade, M. L. Da Silva, A. C. F. Ferreira, and D. P. Carvalho, "Tissue-specific deiodinase regulation during food restriction and low replacement dose of leptin in rats," American Journal of Physiology, vol. 296, no. 5, pp. E1157-E1163, 2009.

[38] M. Ohtake, G. A. Bray, and M. Azukizawa, "Studies on hypothermia and thyroid function in the obese (ob/ob) mouse," American Journal of Physiology, vol. 2, no. 2, pp. 110 $115,1977$.

[39] K. Clément, C. Vaisse, N. Lahlou et al., "A mutation in the human leptin receptor gene causes obesity and pituitary dysfunction," Nature, vol. 392, no. 6674, pp. 398-401, 1998.

[40] I. Sadaf Farooqi, G. Matarese, G. M. Lord et al., "Beneficial effects of leptin on obesity, $\mathrm{T}$ cell hyporesponsiveness, and neuroendocrine/metabolic dysfunction of human congenital leptin deficiency," Journal of Clinical Investigation, vol. 110, no. 8, pp. 1093-1103, 2002.

[41] M. Ghamari-Langroudi, K. R. Vella, D. Srisai, M. L. Sugrue, A. N. Hollenberg, and R. D. Cone, "Regulation of thyrotropinreleasing hormone-expressing neurons in paraventricular nucleus of the hypothalamus by signals of adiposity," Molecular Endocrinology, vol. 24, no. 12, pp. 2366-2381, 2010.

[42] T. J. Visser, J. L. Leonard, M. M. Kaplan, and P. R. Larsen, "Kinetic evidence suggesting two mechanisms for iodothyronine 5'-deiodination in rat cerebral cortex," Proceedings of the National Academy of Sciences of the United States of America, vol. 79, no. 16, pp. 5080-5084, 1982.

[43] M. J. Schneider, S. N. Fiering, S. E. Pallud, A. F. Parlow, D. L. ST. Germain, and V. A. Galton, "Targeted disruption of the type 2 selenodeiodinase gene (Dio2) results in a phenotype of pituitary resistance to T," Molecular Endocrinology, vol. 15, no. 12, pp. 2137-2148, 2001.

[44] G. A. C. Van Haasteren, E. Linkels, W. Klootwijk et al., "Starvation-induced changes in the hypothalamic content of prothyrotrophin-releasing hormone (proTRH) mRNA and the hypothalamic release of proTRH-derived peptides: role of the adrenal gland," Journal of Endocrinology, vol. 145, no. 1, pp. 143-153, 1995.

[45] S. Diano, F. Naftolin, F. Goglia, and T. L. Horvath, "Fastinginduced increase in type II iodothyronine deiodinase activity and messenger ribonucleic acid levels is not reversed by thyroxine in the rat hypothalamus," Endocrinology, vol. 139, no. 6, pp. 2879-2884, 1998.

[46] H. M. Tu, S. W. Kim, D. Salvatore et al., "Regional distribution of type 2 thyroxine deiodinase messenger ribonucleic acid in rat hypothalamus and pituitary and its regulation by thyroid hormone," Endocrinology, vol. 138, no. 8, pp. 3359-3368, 1997.

[47] A. Guadaño-Ferraz, M. J. Obregón, D. L. Germain, and J. Bernal, "The type 2 iodothyronine deiodinase is expressed primarily in glial cells in the neonatal rat brain," Proceedings of the National Academy of Sciences of the United States of America, vol. 94, no. 19, pp. 10391-10396, 1997.

[48] L. M. Roberts, K. Woodford, M. Zhou et al., "Expression of the thyroid hormone transporters monocarboxylate transporter-8 (SLC16A2) and organic ion transporter-14 (SLCO1C1) at the blood-brain barrier," Endocrinology, vol. 149, no. 12, pp. 62516261,2008
[49] H. Heuer, M. K. Maier, S. Iden et al., "The monocarboxylate transporter 8 linked to human psychomotor retardation is highly expressed in thyroid hormone-sensitive neuron populations," Endocrinology, vol. 146, no. 4, pp. 1701-1706, 2005.

[50] J. E. Silva, M. B. Gordon, and F. R. Crantz, "Qualitative and quantitative differences in the pathways of extrathyroidal triiodothyronine generation between euthyroid and hypothyroid rats," Journal of Clinical Investigation, vol. 73, no. 4, pp. 898907, 1984.

[51] B. Gereben, A. M. Zavacki, S. Ribich et al., "Cellular and molecular basis of deiodinase-regulated thyroid hormone signaling," Endocrine Reviews, vol. 29, no. 7, pp. 898-938, 2008.

[52] P. N. Riskind, J. M. Kolodny, and P. R. Larsen, “The regional hypothalamic distribution of type II 5'-monodeiodinase in euthyroid and hypothyroid rats," Brain Research, vol. 420, no. 1, pp. 194-198, 1987.

[53] A. Coppola, Z. W. Liu, Z. B. Andrews et al., "A central thermogenic-like mechanism in feeding regulation: an interplay between arcuate nucleus T3 and UCP2," Cell Metabolism, vol. 5, no. 1, pp. 21-33, 2007.

[54] D. Ricquier, "Respiration uncoupling and metabolism in the control of energy expenditure," Proceedings of the Nutrition Society, vol. 64, no. 1, pp. 47-52, 2005.

[55] M. L. Reitman, Y. He, and D.-W. Gong, "Thyroid hormone and other regulators of uncoupling proteins," International Journal of Obesity, vol. 23, pp. S56-S59, 1999.

[56] J. K. Young, "Anatomical relationship between specialized astrocytes and leptin-sensitive neurones," Journal of Anatomy, vol. 201, no. 1, pp. 85-90, 2002.

[57] H. Hsuchou, Y. He, A. J. Kastin et al., "Obesity induces functional astrocytic leptin receptors in hypothalamus," Brain, vol. 132, no. 4, pp. 889-902, 2009.

[58] A. Alkemade, E. C. Friesema, U. A. Unmehopa et al., "Neuroanatomical pathways for thyroid hormone feedback in the human hypothalamus," Journal of Clinical Endocrinology and Metabolism, vol. 90, no. 7, pp. 4322-4334, 2005.

[59] A. C. Bianco, D. Salvatore, B. Gereben, M. J. Berry, and P. R. Larsen, "Biochemistry, cellular and molecular biology, and physiological roles of the iodothyronine selenodeiodinases," Endocrine Reviews, vol. 23, no. 1, pp. 38-89, 2002.

[60] A. Campos-barros, T. Hoell, A. Musa et al., "Phenolic and tyrosyl ring iodothyronine deiodination and thyroid hormone concentrations in the human central nervous system," Journal of Clinical Endocrinology and Metabolism, vol. 81, no. 6, pp. 2179-2185, 1996.

[61] H. M. Tu, G. Legradi, T. Bartha, D. Salvatore, R. M. Lechan, and P. R. Larsen, "Regional expression of the type 3 iodothyronine deiodinase messenger ribonucleic acid in the rat central nervous system and its regulation by thyroid hormone," Endocrinology, vol. 140, no. 2, pp. 784-790, 1999.

[62] R. P. Peeters, P. J. Wouters, E. Kaptein, H. Van Toor, T. J. Visser, and G. Van Den Berghe, "Reduced activation and increased inactivation of thyroid hormone in tissues of critically ill patients," Journal of Clinical Endocrinology and Metabolism, vol. 88, no. 7, pp. 3202-3211, 2003.

[63] F. J. P. Ebling and P. Barrett, "The regulation of seasonal changes in food intake and body weight," Journal of Neuroendocrinology, vol. 20, no. 6, pp. 827-833, 2008.

[64] P. Barrett, F. J. P. Ebling, S. Schuhler et al., "Hypothalamic thyroid hormone catabolism acts as a gatekeeper for the seasonal control of body weight and reproduction," Endocrinology, vol. 148, no. 8, pp. 3608-3617, 2007. 


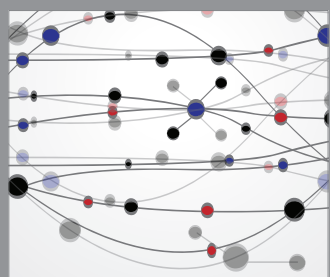

The Scientific World Journal
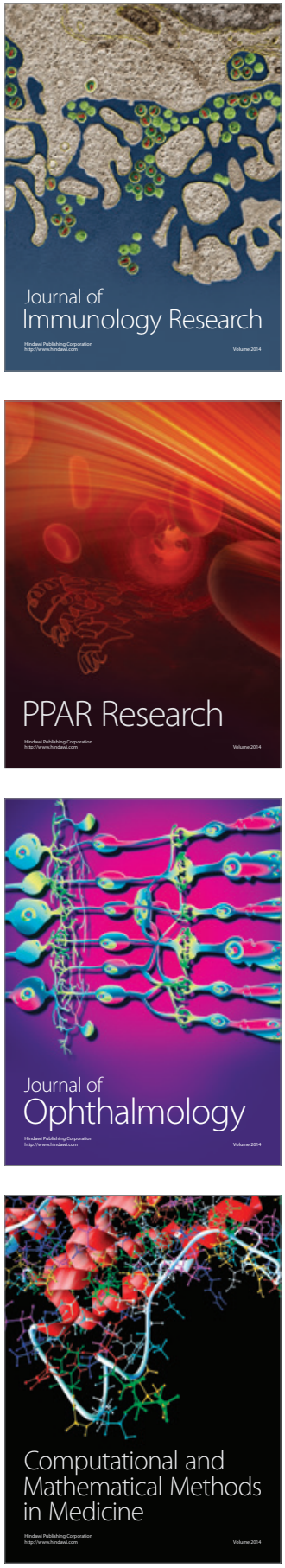

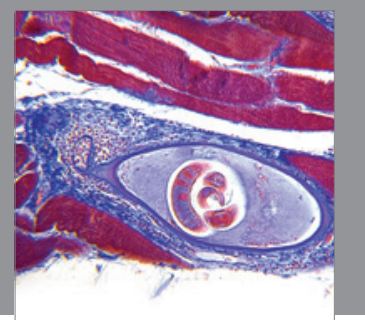

Gastroenterology

Research and Practice
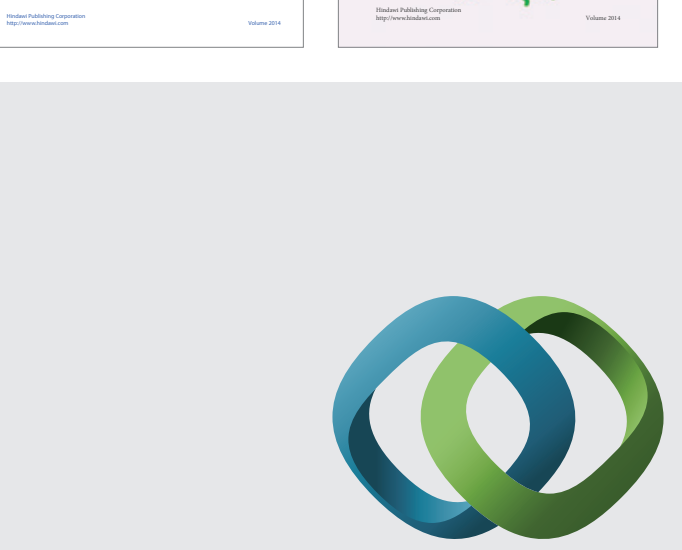

\section{Hindawi}

Submit your manuscripts at

http://www.hindawi.com
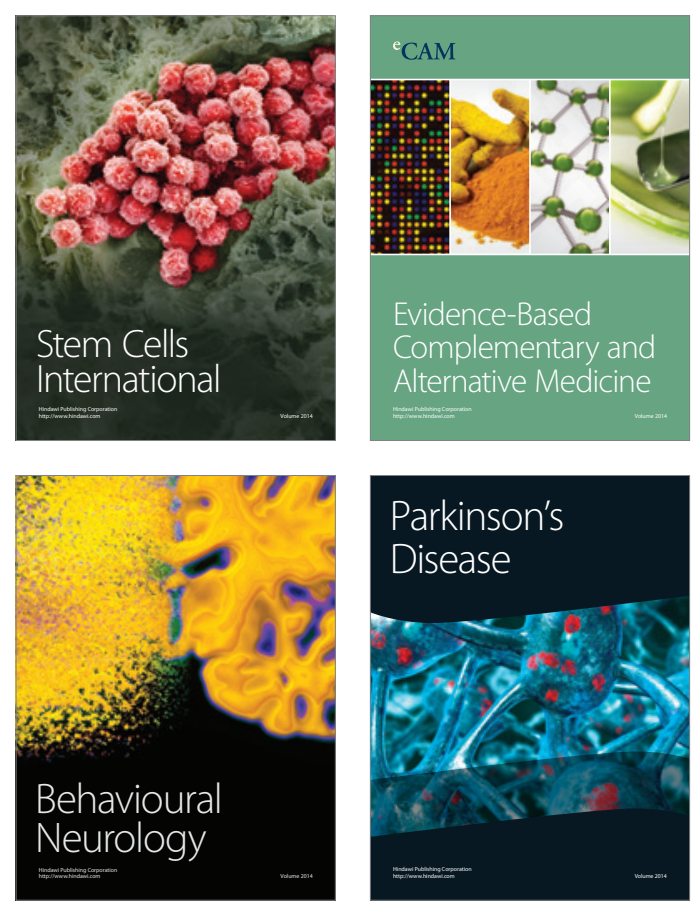

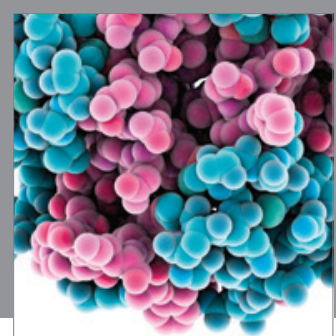

Journal of
Diabetes Research

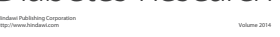

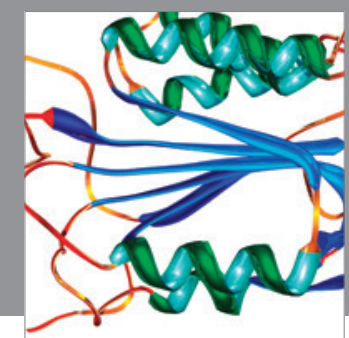

Disease Markers
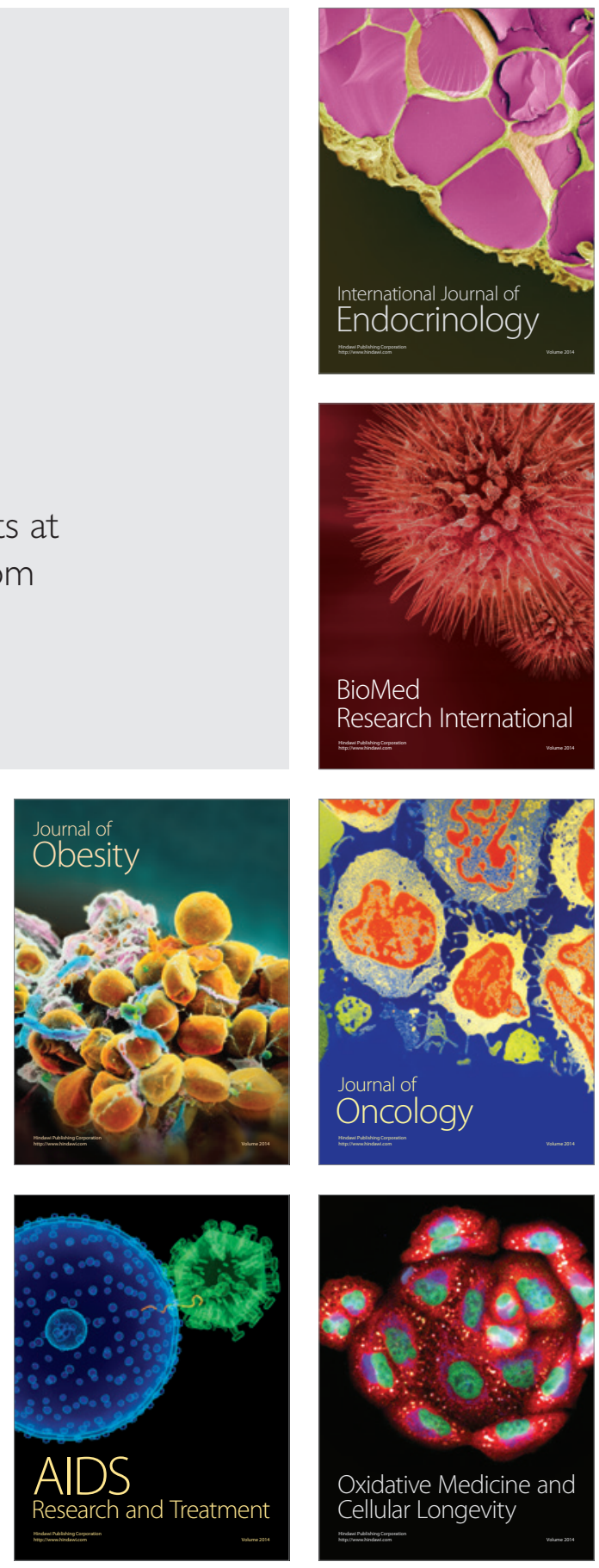